\title{
PowerEnergy2017-3276
}

\section{DEVELOPMENT IN PARAFFIN BASED THERMAL STORAGE SYSTEM THROUGH SHELL AND TUBES HEAT EXCHANGER WITH VERTICAL FINS}

\author{
Zakir Khan \\ Nano Corr., Energy and Modelling Research \\ Group, Faculty of Science and Technology, \\ Bournemouth University. \\ Bournemouth, Dorset, UK
}

\author{
Zulfiqar Ahmad Khan \\ Nano Corr., Energy and Modelling Research \\ Group, Faculty of Science and Technology, \\ Bournemouth University. \\ Bournemouth, Dorset, UK
}

\begin{abstract}
Researchers are committed to develop robust and responsive technologies for renewable energy sources to avert from reliance on fossil fuels, which is the main cause of global warming and climate change. Solar energy based renewable energy technologies are valued as an important substitute to bridge gap between energy demand and generation. However, due to varying and inconsistent nature of solar energy during weather fluctuations, seasonal conditions and night times, the complete utilisation of technology is not guaranteed. Therefore, thermal energy storage (TES) system is considered as an imperative technology to be deployed within solar energy systems or heat recovery systems to maximise systems efficiency and to compensate for varying thermal irradiance. TES system can capture and store the excess amount of thermal energy during solar peak hours or recover from systems that would otherwise discard this excess amount of thermal energy. This stored energy is then made available to be utilised during solar off peak hours or night times.

Phase change material (PCM) based TES system is appraised as a viable option due to its excellent adoption to solar and heat recovery systems, higher thermal storage density and wide range of materials availability. However, due to its low thermal conductivity $(\cong 0.2 \mathrm{~W} / \mathrm{mK})$, the rapid charging and discharging of TES system is a challenge. Therefore, there is a need for efficient and responsive heat exchange mechanism to boost the heat transfer within PCM.

In this study, transient analysis of two-dimensional computational model of vertical shell and tube based TES system is conducted. Commercial grade paraffin (RT44HC) is employed in shell as thermal storage material due to its higher thermal storage density, thermo-physical stability and compatibility with container material. Water is made to flow in tubes as heat transfer fluid. In this numerical study, the parametric investigations are performed to determine the enhancement in charging rate, discharging rate and thermal
\end{abstract}

storage capacity of TES system. The parametric investigations involve geometrical orientations of tubes in shell with and without fins, inlet temperature and volume flow rate of HTF.

It is evident from numerical results that due to increase in effective surface area for heat transfer by vertical fins, the charging and discharging rate of paraffin based TES system can be significantly increased. Due to inclusion of vertical fins, conduction heat transfer is dominant mode of heat transfer in both charging and discharging processes. Furthermore, vertical fins do not restrict natural convection or buoyancy driven flow as compared to horizontal fins. Similarly, the inlet temperature has a noticeable impact on both charging and discharging process. In melting process, the sensible enthalpy is boosted due to rise in inlet temperature and thus the whole system thermal storage capacity is enhanced. Likewise, the effect of volume flow rate of HTF on charging and discharging rate is moderate as compared to inlet temperature of HTF. The numerical results are validated by experimental results.

To conclude, these findings present an understanding into how to increase charging and discharging rate of TES system so as to provide feasible design solutions for widespread domestic and commercial utilisation of TES technology.

\section{INTRODUCTION}

Dependency on fossil fuels for power generation has instigated immense threat to clean air and ozone layer which are main sources behind recent global warming and climate change $[1,2]$. Likewise, world power consumption is continuously increasing with economic development. Therefore, there is a need of developments in renewable energy sector to minimise reliance on fossil fuels for power generation.

Solar energy is termed as decisive renewable energy source for its enormous quantity of free and clean incident solar radiations. Thus, the interest in utilising solar energy source to meet global energy demand has been boosted in recent years [3]. Nano Corr., Energy and Modelling Research Group at 
Bournemouth University, UK is keenly engaged in developing robust and responsive technologies to attain maximum benefit from solar energy sources [4-6].

However, due to highly unforeseeable and dubious nature of solar energy caused by weather fluctuations and day/night times, the far-reaching benefits are highly affected. In order to respond to unpredictable nature of solar energy, thermal energy storages (TES) system is gauged as a suitable option due to its great acceptance to solar energy. TES system can capture the excess thermal energy at solar peak periods and bring it into service during solar off-peak periods or night-time.

TES system is categorised into three groups, which are sensible heat storage (SHS), latent heat storage (LHS) and thermo-chemical system. In order to store same quantity of thermal energy, the required mass for rocks (SHS) will be seven times to organic paraffin (LHS) and eight times to salt hydrate (LHS) $[7,8]$. Therefore, LHS is regarded as better option due to its higher thermal storage capacity, higher heat of fusion per unit volume, lower vapour pressure, phase change materials (PCM) availability in wide range of temperatures and almost isothermal thermal energy storage and retrieval $[9,10]$.

Despite these favorable properties, PCMs have low thermal conductivity $(\cong 0.2 \mathrm{~W} / \mathrm{mK})$, which hinders rapid charging and discharging of LHS system and thus the practical utilisation is highly affected. Hence, LHS system requires a responsive heat transfer mechanism within PCM to boost thermal charging rate and discharging rate. In past 2 decades, substantial research has been conducted to identify techniques for enhancing thermal performance of LHS system. Among all techniques, geometrical configuration with extended surfaces[11, 12], addition of high thermal conductivity additives $[13,14]$ and encapsulation techniques $[15,16]$ have been studied the most.

In this paper, two dimensional transient computational model of shell and tube with longitudinal fins based LHS system is simulated to find effective parameters that promise rapid melting and solidification of PCM in LHS system. This paper is focused on studying impact of longitudinal fins, geometrical configurations of fins and operating conditions on thermal performance of LHS system. Moreover, experimental examinations are conducted to validate the simulated computational model. This paper will give an insight and understanding into how to improve charging and discharging rate of LHS system so as to enlarge its practical utilisation in domestic and industrial applications.

\section{PHYSICAL MODEL}

The schematic of LHS system connected to flat-plate solar collector is represented in Fig. 1. The model is comprised of LHS tank, flat-plate solar collector, pump and connection to mains water supply. The serpentine type flat-plate solar collector is previously designed and developed in Nano Corr., Energy and Modelling Research Group at Bournemouth University, UK by Helvaci and Khan [4, 5]. Shell and tube heat exchange mechanism is designed for LHS tank, as depicted in Fig. 2. The thickness, height and outer diameter of shell are 1 $\mathrm{mm}, 320 \mathrm{~mm}$ and $450 \mathrm{~mm}$, respectively. The outer diameter and thickness of tube is $22 \mathrm{~mm}$ and $1 \mathrm{~mm}$, respectively. Tubes are connected with longitudinal fins. The length, height and thickness of longitudinal fins are $40 \mathrm{~mm}, 230 \mathrm{~mm}$ and $1.5 \mathrm{~mm}$, respectively. Copper is used as construction material for shell, tube and fins. Paraffin (RT44HC) is employed in shell as PCM, due to its excellent chemical stability, compatibility with copper, high latent heat storage capacity and low cost $[12,17]$. The thermo-physical characteristics of RT44HC are listed in Table 1. Water is used as heat transfer fluid (HTF) in tube. The flow pattern of water within LHS tank is represented by blue arrows in Fig. 2.

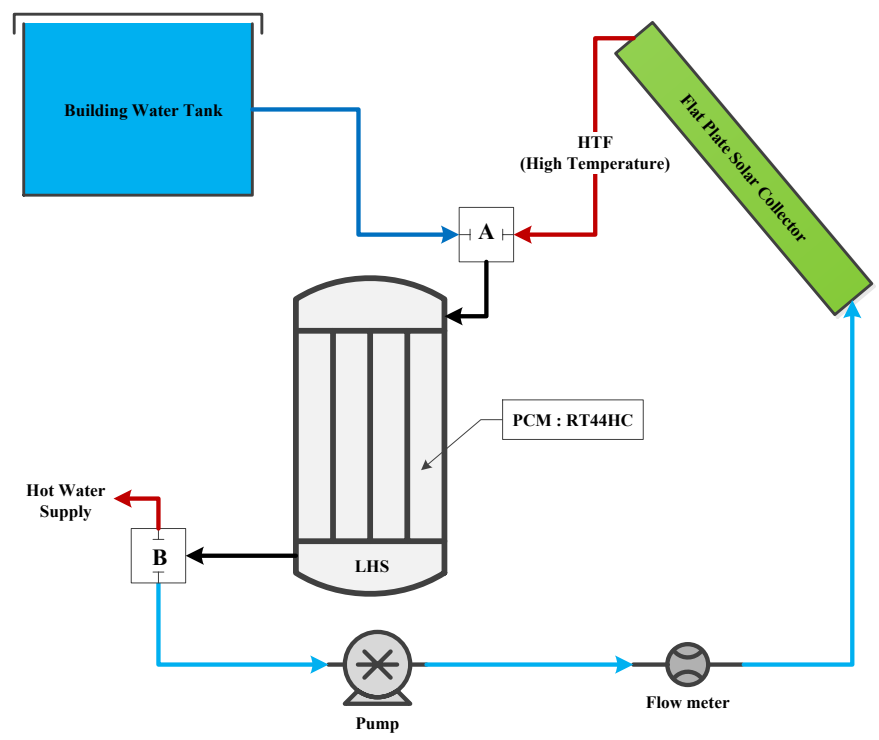

Fig. 1 Schematic of LHS system with flat plate solar collector

During melting process, water from mains supply is initially run through the whole system to make sure that the system is completely filled with water. Now, water supply from mains is turned off to make a close loop. Water is pumped through flat-plate solar collector, where solar radiations are converted to thermal energy. Thermal energy is transferred to water and therefore, it rises water temperature. Water at high temperature is now directed to pass through tubes in LHS tank, where it loses thermal energy to PCM. Thermal energy from water charges LHS system by melting PCM. The closed cycle is repeated until the entire mass of PCM is melted.

During solidification process, high temperature water supply from flat-plate collector is turned off at point $\mathrm{A}$, as shown in Fig. 1. Also, the connection between LHS tank and pump is switched off at point B. Now, the connections for mains supply at point $\mathrm{A}$ and hot water supply at point $\mathrm{B}$ are switched on. Cold water from mains is made to run through tubes in LHS tank, where it extracts thermal energy from PCM. Solidification of PCM starts as thermal energy is extracted. Open cycle is stopped once whole mass of PCM is solidified.

Table 1

Thermo-physical properties of RT44HC [6, 17] 
Phase transition temperature $T_{p c}$

$315.15-317.15 \mathrm{~K}$

Latent heat of fusion

$255(\mathrm{~kJ} / \mathrm{kg})$

Specific heat $C_{p}$

Thermal conductivity $k$

Density $\rho$

Dynamic viscosity $\mu$

Coefficient of thermal expansion $\beta$

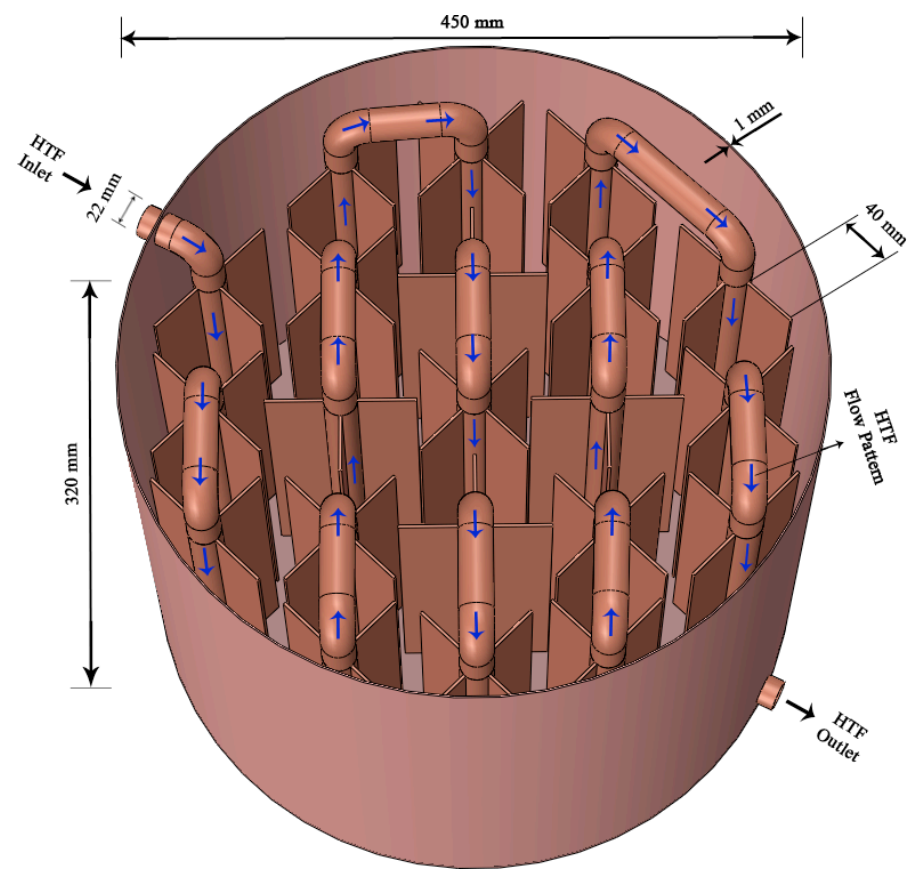

Fig. 2 Sketch of physical model of shell and tube based LHS tank

\section{NUMERICAL MODEL AND BOUNDARY CONDITIONS}

Numerical model for investigating phase transition rate and thermal storage capacity of LHS system is based on conservation of mass, momentum and energy equations. The conservation of mass equation is:

$$
\frac{\partial \rho}{\partial t}+\rho \nabla \mathbf{u}=0
$$

where $\mathbf{u}$ and $\rho$ represent velocity vector and density, respectively. Similarly, momentum equation is expressed as follow:

$$
\rho \frac{\partial \mathbf{u}}{\partial t}+\rho(\mathbf{u} \cdot \nabla) \mathbf{u}=-\nabla p+\mu \Delta \mathbf{u}+\mathbf{F}+S \mathbf{u}
$$

where $p, \mu, \mathbf{F}$ and $S \mathbf{u}$ represent pressure, dynamic viscosity, buoyant force vector and momentum source term, respectively. Buoyant force term $\mathbf{F}$ in Eq. (2) can be calculated by employing Boussinesq approximation [18], as follow:

$$
F=\rho \mathbf{g} \beta\left(T-T_{r e f}\right)
$$

where $\beta$ and $T_{\text {ref }}$ represent coefficient of thermal expansion and reference phase transition temperature. Similarly, momentum source term $S \mathbf{u}$ can be calculated by implementing Kozeny-Carman equation, which is calculated by using Darcy law for flow in porous medium, as follow[19]:

$$
S \mathbf{u}=\frac{\kappa(1-f)^{2}}{\left(\alpha+f^{3}\right)} \mathbf{u}
$$

where $\kappa, \alpha$ and $f$ represent mushy zone constant, small constant value to avoid division by zero and fraction of phase transition, respectively. In current study, $\kappa$ is set to $10^{6}$ and $\alpha$ to $10^{-3}$. Likewise, $f$ can be described as follow:

$$
f=\left\{\begin{array}{cc}
0 & T<T_{s} \\
\frac{T-T_{s}}{T_{l}-T_{s}} & T_{s} \leq T \leq T_{l} \\
1 & T>T_{l}
\end{array}\right.
$$

where $T_{s}$ and $T_{l}$ represent temperature of solid zone and liquid zone of PCM, respectively. Phase change of PCM initiates during interval of $T_{s} \leq T \leq T_{l}$. Likewise, the conservation of energy is illustrated as follow:

$$
\rho \frac{\partial\left(C_{p} T\right)}{\partial t}+\rho \nabla \cdot\left(C_{p} T \mathbf{u}\right)=k \Delta T+q
$$

where $C_{p}, T, k$ and $q$ represent specific heat at constant pressure, temperature, thermal conductivity and heat source term, respectively. During phase transition, the effective specific heat capacity can be obtained by differentiating specific enthalpy of LHS system with temperature [6], as follow: 


$$
C_{p}=\frac{1}{\rho}\left(f_{s} \rho_{s} C_{p, s}+f_{l} \rho_{l} C_{p, l}\right)+\left(H_{l}-H_{s}\right) \frac{\partial}{\partial T}\left[\frac{\left(f_{l} \rho_{l}-f_{s} \rho_{s}\right)}{2 \rho}\right]
$$

where $H$ represents specific enthalpy of LHS system. Solid and liquid phases of PCM are represented by indices $S$ and $l$, respectively.

During melting process, the entire LHS system is assumed to be at initial room temperature, which is $291.15 \mathrm{~K}$. As discussed in Table 1, the phase transition temperature of PCM is $315.15 \mathrm{~K}$. Therefore, the initial temperature of LHS system guarantees that entire mass of PCM is in solid phase. Inlet temperature of HTF is set to three constant boundary temperatures, which have a temperature difference of $10 \mathrm{~K}, 15 \mathrm{~K}$ and $20 \mathrm{~K}$ to phase transition temperature of PCM, respectively.

Likewise in solidification process, LHS system is set to $325.15 \mathrm{~K}$, which has a temperature difference of $10 \mathrm{~K}$ with phase transition temperature. Therefore, it shows that initially entire mass of PCM is in liquid phase. In solidification process, the municipal cold water is employed as HTF. Thus, three inlet temperatures of HTF are investigated, which are $285.15 \mathrm{~K}$, $288.15 \mathrm{~K}$ and $293.15 \mathrm{~K}$, respectively.

\section{COMPUTATIONAL MODEL}

Finite element analysis approach is implemented to discretise aforementioned governing equations. Coupled thermal energy transfer and non-isothermal techniques are adopted to simultaneously solve governing equations for both HTF and PCM. Second order backward differentiation formula is exercised to ensure relative tolerance for each time step. Relative tolerance is kept at constant value of 0.001 . In order to simplify the computational model, the value for inlet temperature of HTF is assumed to be constant. Likewise, the influence of mesh size and time steps on phase transition rate is examined by conducting comparative investigations at constant inlet temperature. As depicted in Table 2, for initial three cases, the time step is kept constant at 1 min whereas mesh size is varied. The result indicates that for constant time step, the phase transition time for entire PCM in LHS tank is almost similar for case II and case III. However, a significant difference is noticed in phase transition time between case I and case II. Likewise, in case IV and case V, the time step is varied whereas mesh size is kept constant. It is noticed that the phase transition time for case IV and case $\mathrm{V}$ is having an insignificant percent error of 1.35 and 2.03 as compared to case II.

Therefore, the chosen time step and mesh numbers for this computational model are $1 \mathrm{~min}$ and 57861, respectively. Fig. 3 depicts mesh configuration adopted for this computational model. Parametric sweep is implemented to investigate the impact of various operating conditions on phase transition rate and thermal storage capacity.

Table 2

Validation of mesh independency and time stepping [6]

\begin{tabular}{lllll}
\hline Case & $\begin{array}{l}\text { Mesh } \\
\text { Numbers }\end{array}$ & $\begin{array}{l}\text { Time step } \\
(\mathrm{min})\end{array}$ & $\begin{array}{l}\text { Melt time } \\
(\mathrm{min})\end{array}$ & Percent Error \\
\hline I & 28674 & 1 & 396 & 10.6 \\
II & 57861 & 1 & 443 & - \\
III & 61932 & 1 & 441 & 0.45 \\
IV & 57861 & 0.25 & 437 & 1.35 \\
V & 57861 & 0.5 & 452 & 2.03 \\
\hline
\end{tabular}

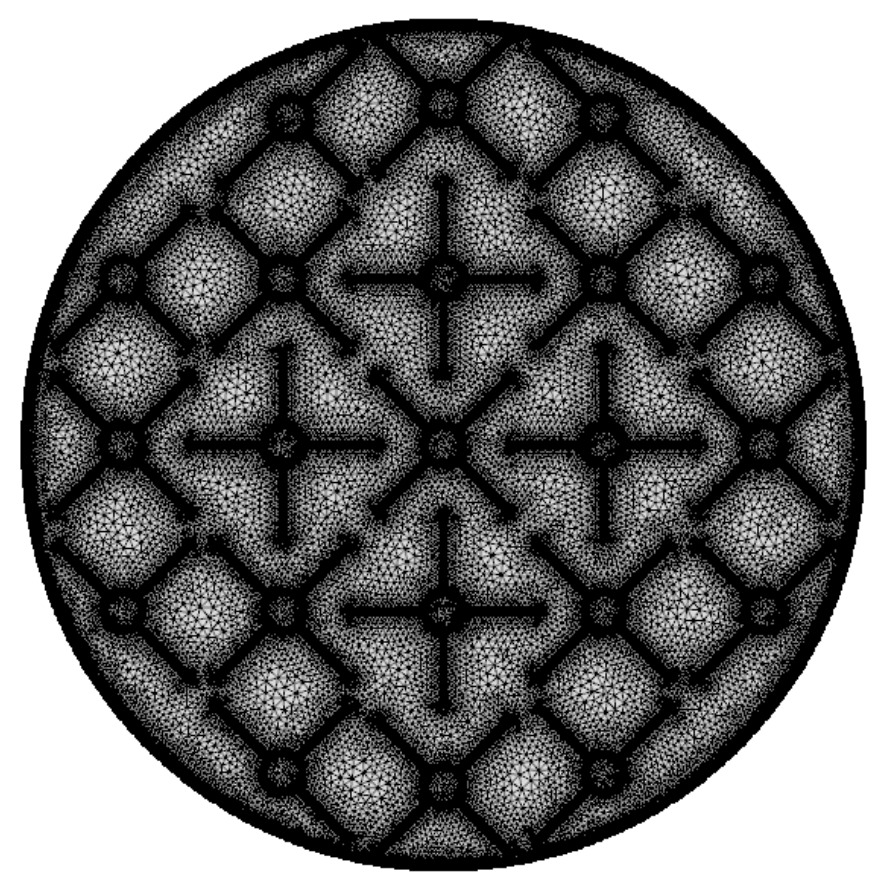

Fig. 3 Mesh configuration of shell and tube with longitudinal fins LHS tank

\section{RESULTS AND DISCUSSION}

In this section, the results attained from numerical investigations and experimental examinations are discussed.

\section{PERFORMANCE OF TUBE IN SHELL WITH AND WITHOUT FINS}

Prior to investigating thermal performance of shell and tube with fins, the computational model is implemented to shell and tube without fins. The inlet temperature of HTF is fixed at $335.15 \mathrm{~K}$. Four data points are selected to inspect the thermal performance of the system, as depicted in Fig. 4. It is noticed that due to less surface area for heat transfer, the rise in temperature is very slow. It is also observed that although the temperature difference between HTF and PCM in inlet zone is higher, it still requires 4.7 hours for complete melting of PCM. Likewise, the PCM in outlet zone needs almost 6.7 hours to completely melt. It shows that due to low thermal conductivity of PCM, the thermal performance of shell and tube heat exchanger without fins is poor. Thus, LHS system demands a geometrical configuration that guarantees rapid charging and discharging. 


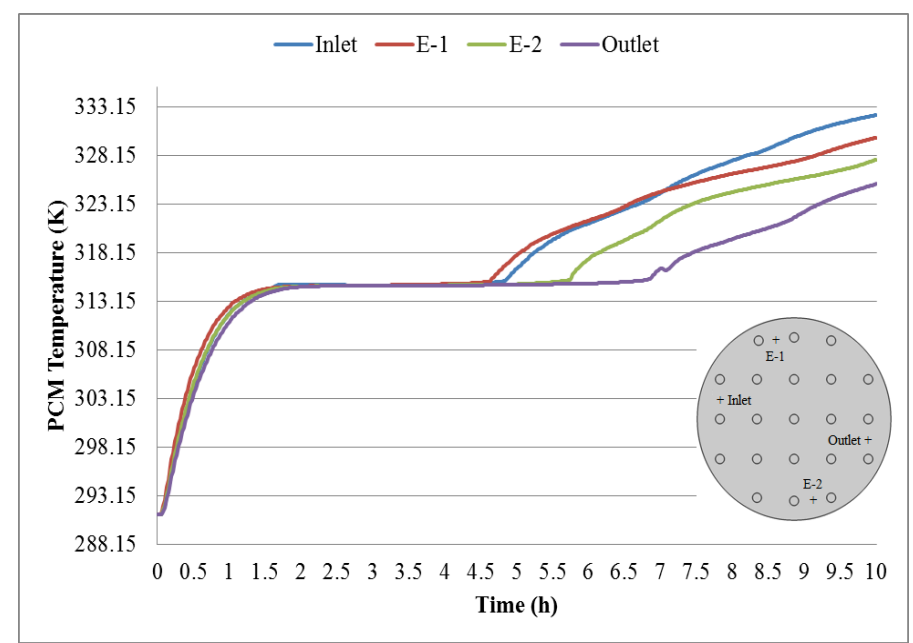

Fig. 4 Temperature plot of PCM in shell and tube without fins configuration. Inlet temperature is set to $335.15 \mathrm{~K}$. Four zones for inspecting temperature data within LHS tank are selected: 1) Inlet 2) Exterior E-1 3) Exterior E-2 4) Outlet.

Thermal performance of shell and tube heat exchanger with longitudinal fins is illustrated in Fig. 5. It is noticed that due to inclusion of longitudinal fins, the effective area for heat transfer increases which enhances thermal performance and heat distribution. As depicted in Fig. 5, the rise in temperature is faster as compared to shell and tube with no fins configuration. In this case, the inlet zone is completely melted in 1.7 hours and outlet zone in 2.25 hours. Melting time in inlet zone for shell and tube with fins configurations is reduced by $63.82 \%$ as compared to shell and tube configuration without fins. Therefore, it is recommended to use longitudinal fins to attain higher phase transition rate of LHS system.

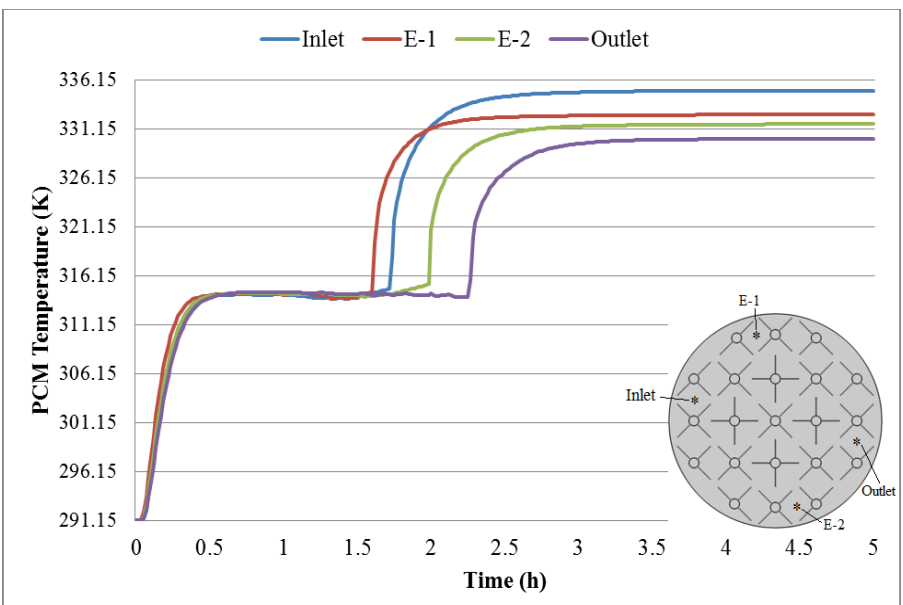

Fig. 5 Temperature plot of PCM in shell and tube with longitudinal fins orientation. Inlet temperature is kept constant at 335.15K.

\section{GEOMETRICAL CONFIGURATIONS OF FINS}

The geometrical configurations of longitudinal fins significantly influence the thermal behavior of LHS system. Therefore, parametric investigations are conducted to identify the impact of fins length and fins thickness on thermal storage behavior and melting rate. In all cases, the inlet temperature of LHS system is kept constant at $335.15 \mathrm{~K}$.

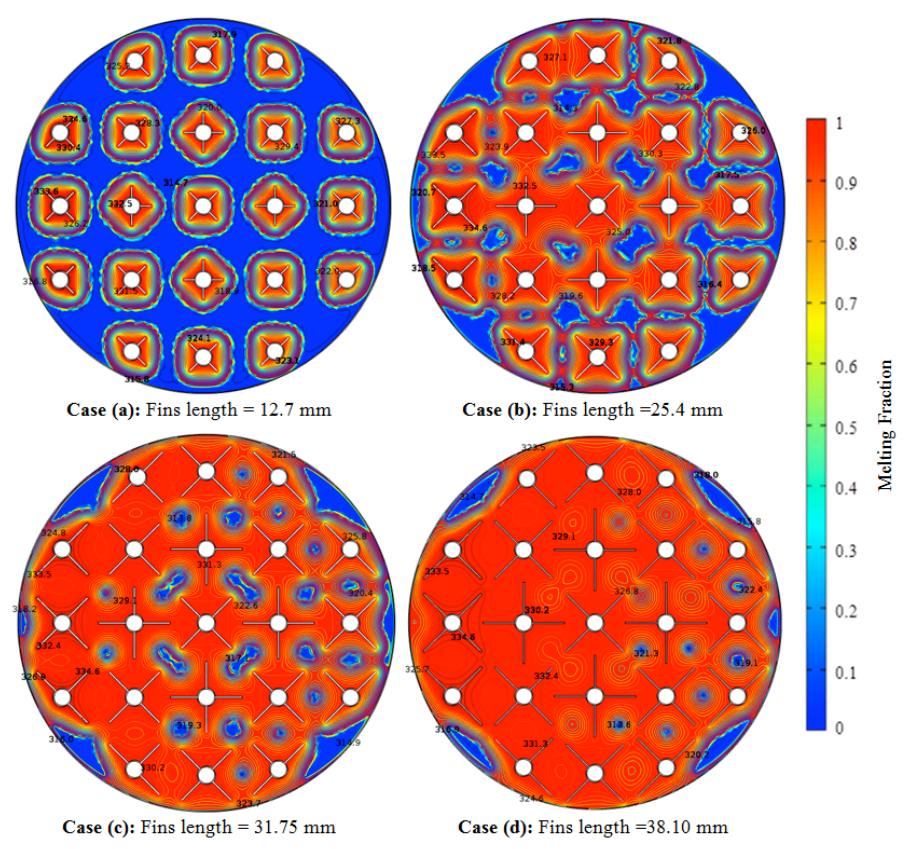

Fig. 6 Melting fraction and thermal contours of LHS system in response to varied fins lengths. Inlet temperature is set to $335.15 \mathrm{~K}$.
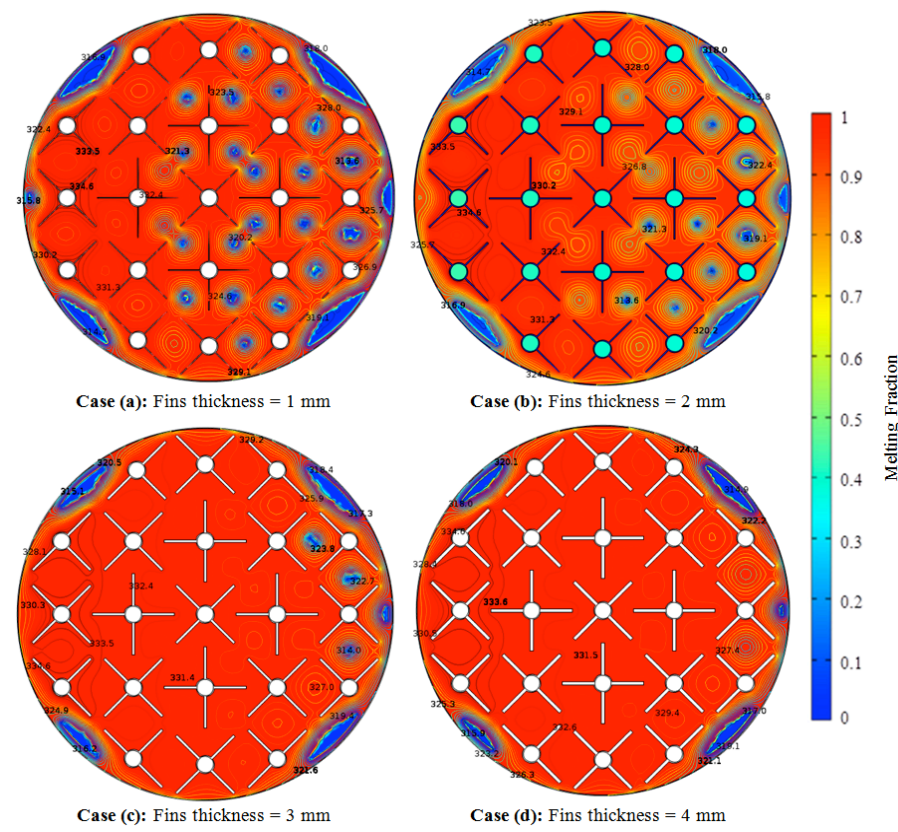

Case (d): Fins thickness $=4 \mathrm{~mm}$

Fig. 7 Impact of fins thickness on melting fraction after charging LHS system with constant inlet temperature of 335.15 K for two hours. 
It can be noticed from Fig. 6 that due to an increase in fins length, the melting rate of PCM in LHS system is significantly enhanced. Fins lengths are investigated in range of $12.70 \mathrm{~mm}$ to $38.10 \mathrm{~mm}$. As depicted in Fig. 6, the distribution of temperature in entire system for $38.10 \mathrm{~mm}$ fins is better than others cases due to an increase in effective surface area for heat transfer. Likewise, after two hours of heat transfer from HTF to PCM at constant inlet temperature, the liquid fraction of PCM for case (a), (b), (c) and (d) are registered to be $64.34 \%, 82.80 \%$, $92.06 \%$ and $96.86 \%$, respectively. It shows that with an increase in fins length, the melting/charging time of LHS system can be significantly reduced. However, thermal storage capacity is slightly reduced due to inclusion of lengthy fins. Thermal storage capacity of $38.10 \mathrm{~mm}$ is $1.94 \%$ lesser than $12.70 \mathrm{~mm}$. Nevertheless, the slight reduction in thermal storage capacity does not diminish the importance of rapid charging and discharging of LHS system produced by inclusion of lengthy fins.

Likewise, the influence of fins thickness ranging from 1 $\mathrm{mm}$ to $4 \mathrm{~mm}$ on thermal behavior of LHS system is studied. During this investigation, the fins length is set constant at 38.10 $\mathrm{mm}$. As shown in Fig. 7, fins thickness displayed a moderate influence on melting rate as compared to fins length. Similarly, the effect on temperature distribution within LHS system is insignificant. The total melting time for case (b), (c) and (d) are reduced by $12.04 \%, 20.37 \%$ and $22.68 \%$ as compared to case (a). However, thermal storage capacity is compromised by using thicker fins. Thermal storage capacity for $4 \mathrm{~mm}$ is decreased by $4.3 \%$ as compared to $1 \mathrm{~mm}$. Thus, it is recommended to use lengthy thin fins.

\section{OPERATING CONDITIONS}

In order to investigate the performance of shell and tube orientation with longitudinal fins under various operating

Time (h)

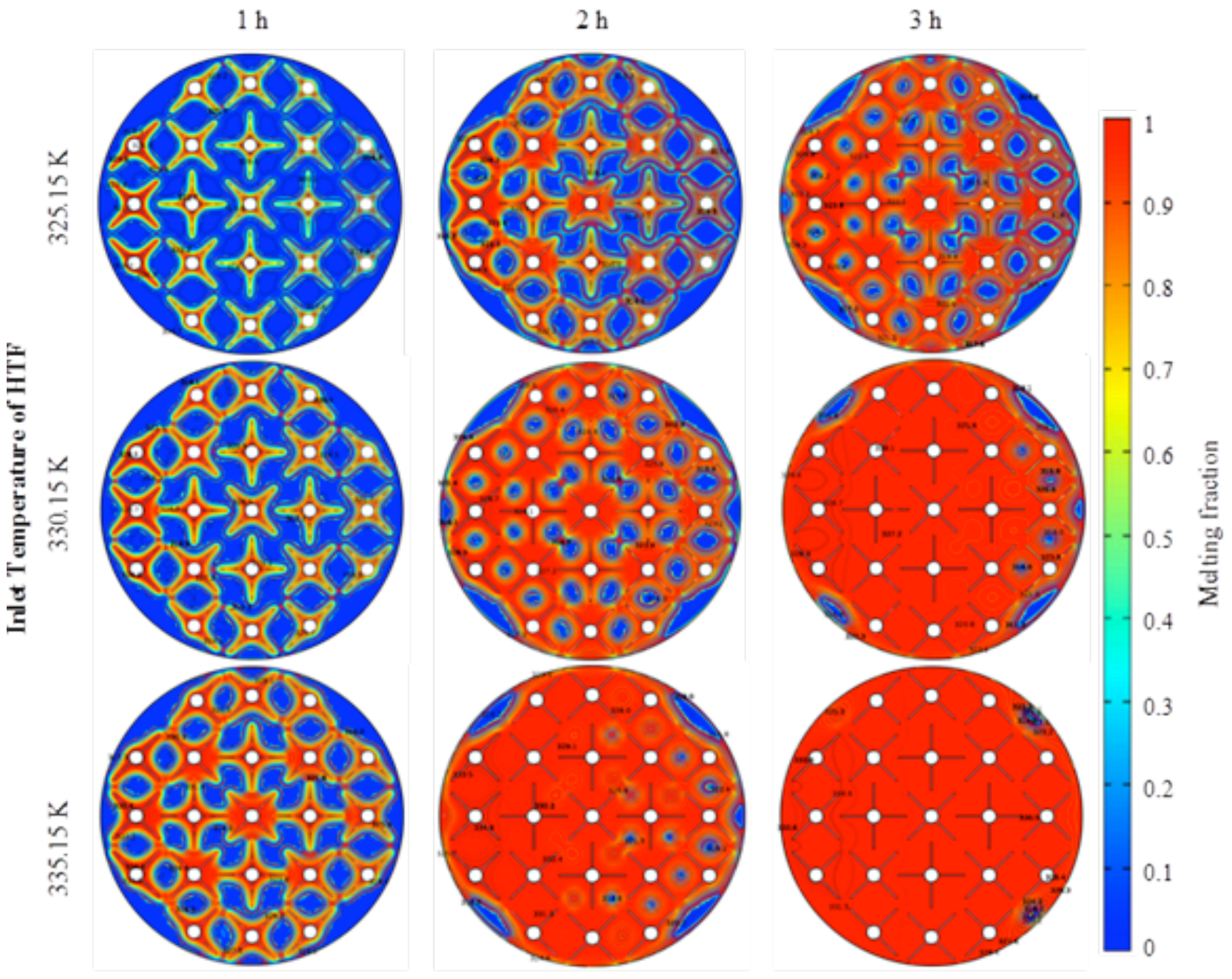


conditions, the inlet temperatures of $325.15 \mathrm{~K}, 330.15 \mathrm{~K}$ and $335.15 \mathrm{~K}$ are inspected in melting process. Likewise, the inlet temperature of $285.15 \mathrm{~K}, 288.15 \mathrm{~K}$ and $293.15 \mathrm{~K}$ are tested in solidification process.

During melting process, it is observed that heat transfer between HTF and PCM is boosted due to higher temperature difference caused by an increase in inlet temperature of HTF. Due to higher heat transfer, the melting rate of PCM improves, as shown in Fig. 8. It can be observed that during $325.15 \mathrm{~K}$ as inlet temperature, due to higher temperature difference between inlet temperature of HTF and PCM in inlet zone (left side of Fig .8), the melting rate is higher and therefore HTF loses thermal energy to PCM. HTF drops temperature as it loses thermal energy. Thus, the melting rate in central zone and outlet zone (right side of Fig. 8) is comparatively lower due to smaller temperature difference.

Similarly, due to rise in inlet temperature, the temperature difference improves throughout the LHS tank, as depicted in Fig. 8. It can be noticed that in case of $335.15 \mathrm{~K}$, almost entire mass of PCM is either in mushy zone or liquid form. After 3 hours of charging at constant inlet temperatures, it is observed that liquid fractions for $325.15 \mathrm{~K}, 330.15 \mathrm{~K}$ and $335.15 \mathrm{~K}$ are $86.71 \%, 97.84 \%$ and $99.9 \%$, respectively. It indicates that with an increase in inlet temperature, the overall charging time of LHS system can be reduced. Moreover, with an increased inlet temperature, the sensible energy of system is boosted. Therefore, a higher overall thermal storage capacity is achieved. Overall system enthalpy can be increased from $317 \mathrm{~kJ} / \mathrm{kg}$ to $345 \mathrm{~kJ} / \mathrm{kg}$ by rising inlet temperature of HTF from $325.15 \mathrm{~K}$ to $335.15 \mathrm{~K}$.

During solidification process, the thermal energy is transferred from PCM to HTF. In this numerical investigation, three inlet temperatures of HTF are tested which are $285.15 \mathrm{~K}$, $288.15 \mathrm{~K}$ and $293.15 \mathrm{~K}$. These values are selected as the temperature of municipal water is in the range of $285.15 \mathrm{~K}$ to $293.15 \mathrm{~K}$. The solidification times for entire LHS tank at all three inlet temperatures are $2.05,2.32$ and 2.78 hours, respectively. Due to higher temperature difference of PCM with $\mathrm{HTF}$ at $285.15 \mathrm{~K}$, the solidification rate is higher.

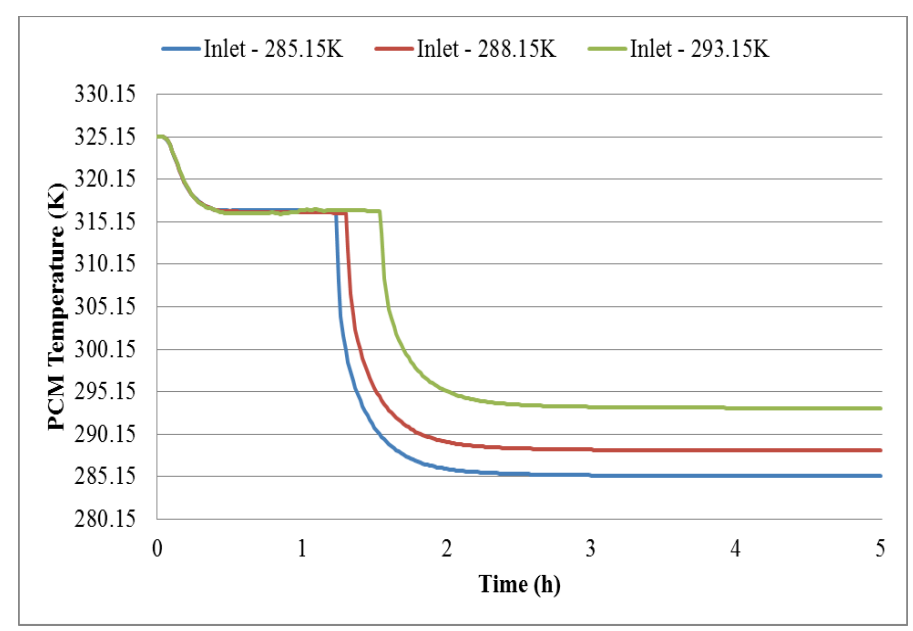

(A)

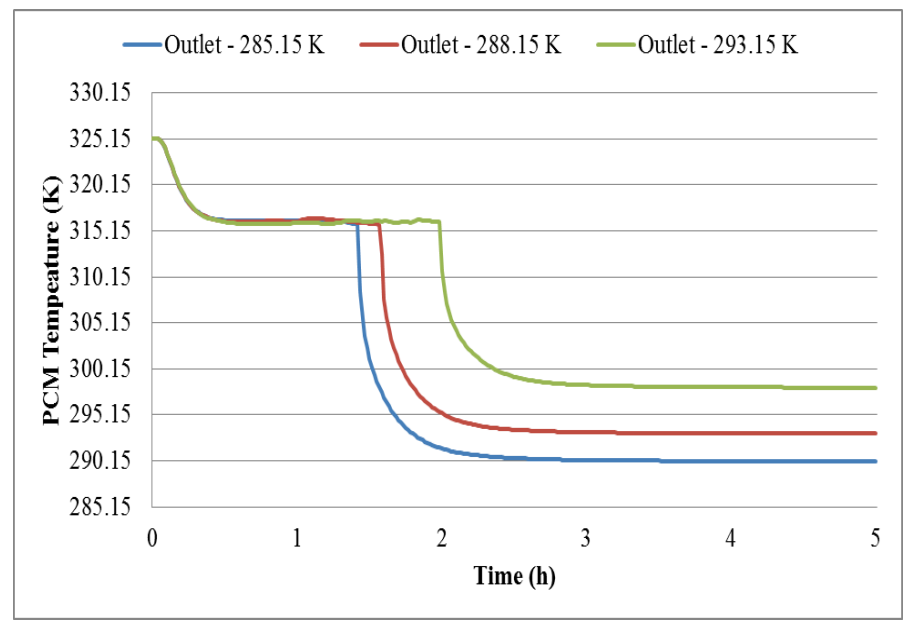

(B)

Fig. 9 Numerical examination of temperature response to PCM at inlet (A) and outlet (B) zones upon three different inlet temperatures

As shown in Fig. 9, thermal energy is promptly extracted from inlet zone with inlet temperature of $285.15 \mathrm{~K}$ as compared to inlet temperature of $293.15 \mathrm{~K}$. Similarly in outlet zone, the solidification of entire PCM requires 1.4 hours and 1.98 hours for inlet temperature of $285.15 \mathrm{~K}$ and $293.15 \mathrm{~K}$, respectively.

\section{EXPERIMENTAL RESULTS}

The experimental setup includes serpentine type flat-plate solar collector, LHS tank, water circulating pump, connections to mains water supply and K-type thermocouples with data acquisition unit. The serpentine type flat-plate solar collector is previously designed and commissioned by Helvaci and Khan $[4,5]$. Based on numerical simulation results, the LHS tank is designed and manufactured as per specifications shown in Fig. 2. Prior to connecting LHS tank to flat-plate solar collector, leak tests are performed to ensure safety and system efficiency as otherwise water seepage will disturb thermo-physical properties of PCM. The joints and elbows are given special attention for any leakage. Initially, high pressure air equals to 4 bar is inserted to LHS tank by connecting it to a compressor. Foamy liquid leak detector is applied to all joints and elbows. After air leak test, the pressurised air is released. Similarly, water leak test is performed to cross check any seepage. In water leak test, the outlet valve is closed and water is pumped through inlet valve to generate pressure within tube loop of LHS tank. The inlet valve is also closed once sufficient pressure is developed. The pressurised water is left within tubes for 48 hours to identify any leakage. No seepage is detected in both air and water leak tests.

In order to conduct experimental investigations, the connections between flat-plate solar collector and LHS tank is made by following the schematic shown in Fig. 1. In data recording system, $\mathrm{K}$ type thermocouples are employed at inlet 
and outlet zone at various depths in LHS tank to investigate the temperature response of PCM during melting and solidification process. Titan FT2 Hall Effect flow meter is utilised to measure and control the flow rate of water. Thermocouples and flow meter are connected to Agilent 34970A data acquisition unit to record data in computer interface. The time step for data recording is set to $10 \mathrm{~s}$.

During melting/charging process, water is initially run from mains to confirm that the system is completely filled with water. Also, it helps in bringing down the temperature of PCM in LHS tank to approximately $291.15 \mathrm{~K}$, which provides a better reference point for comparison. The water supply from mains is then turned off to make a close loop. Water circulating pump is operated to circulate water at various flow rates through flat-plate solar collector, where water absorbs thermal energy from collector and rises its temperature. Water at high temperature is directed through LHS tank, where it releases thermal energy to PCM. Three inlet temperatures of water are tested: $325.15 \mathrm{~K}, 330.15 \mathrm{~K}$ and $335.15 \mathrm{~K}$. Likewise, the various volume flow rate of water range from $1.5 \mathrm{lpm}$ to $3 \mathrm{lpm}$. The range of volume flow rate is selected in accordance to thermal performance of flat-plate solar collector.

In order to examine thermal behavior of PCM against various flow rates of water, the inlet temperature of water to LHS tank is kept constant at $335.15 \mathrm{~K}$ and three volume flow rates are experimented, as shown in Fig. 10. The selected volume flow rates are $2 \mathrm{lpm}, 2.5 \mathrm{lpm}$ and $3 \mathrm{lpm}$. The temperature data in Fig. 10 are collected from thermocouple installed at inlet zone with probe depth of $160 \mathrm{~mm}$ (central depth of LHS tank). It can be noticed from Fig. 10 that with an increase in volume flow rate of water, the melting time of PCM reduces and consequently, the charging time of LHS tank can be decreased. As depicted, the melting time for PCM at inlet zone is reduced by $9.65 \%$ and $22.81 \%$ as the volume flow rate is increased from $2 \mathrm{lpm}$ to $2.5 \mathrm{lpm}$ and $3 \mathrm{lpm}$, respectively. The sensible portion of heat storage, before and after phase transition, almost behaved in a similar manner for all flow rates. However, the latent portion of heat storage is considerably influenced by varying flow rates.

After charging the LHS tank, the entire mass of PCM is in liquid state. In order to conduct solidification/discharging test, the hot water connection between solar collector and LHS tank is turned off and cold water from mains supply is directed through LHS tank. Water extracts thermal energy from PCM as it runs through pipes of LHS tank. Solidification of PCM begins as it starts losing the latent portion of thermal energy to water. Experimental examinations are conducted to identify the impact of varying flow rates of cold water on thermal performance of PCM in LHS tank. Three volume flow rates of water are experimentally examined: $1.5,2$ and $2.5 \mathrm{lpm}$. Inlet temperature of cold water for all cases is constant at $285.15 \mathrm{~K}$. As depicted in Fig. 11, the varying flow rate of water has a minimal impact on thermal performance of LHS system in solidification process. The temperature profiles for all three flow rates are almost identical. Due to higher temperature difference between inlet water temperature and liquid PCM, the extraction of thermal energy from PCM is rapid. Therefore, the phase transition of PCM from liquid to solid at inlet zone is faster than other zones within LHS tank.

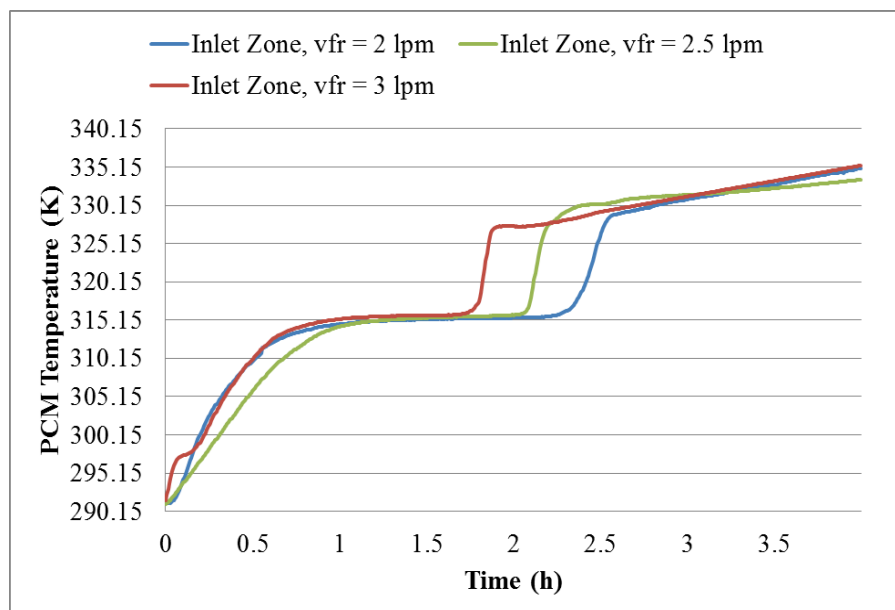

Fig. 10 Experimental examination of temperature response of PCM during melting process at various time intervals for various flow rates. The inlet temperature of HTF is kept constant at $335.15 \mathrm{~K}$.

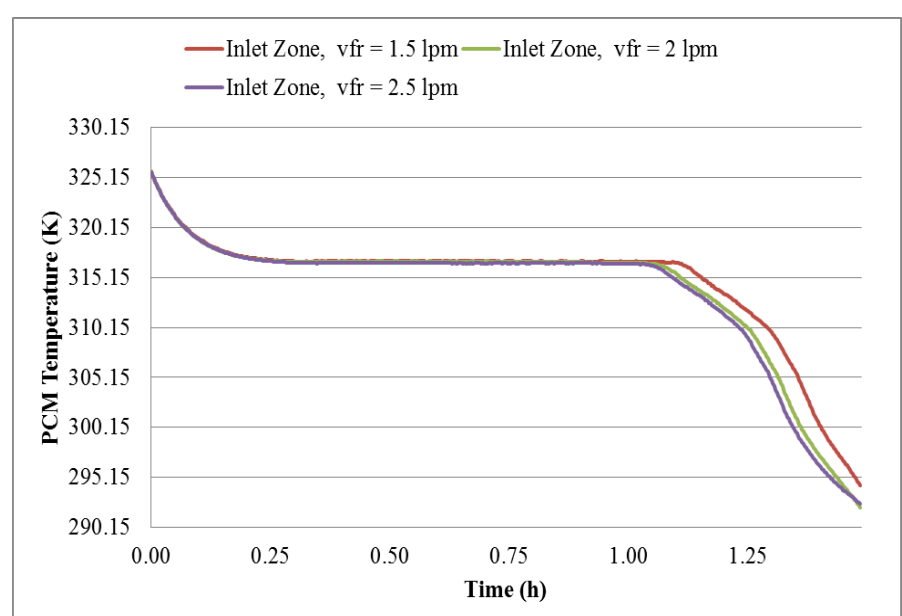

Fig. 11 Experimental investigation of temperature response of PCM during solidification process at various time intervals for various flow rates. The inlet temperature of water is kept constant at $285.15 \mathrm{~K}$.

For validation purpose, experimental results at inlet zone for charging process is compared with numerical model simulation results, as shown in Fig. 12. The experimental data is collected from thermocouple at inlet zone with probe at central depth of LHS tank. It can be seen that both results are in good agreement, however the slight variation in experimental results is caused due to buoyancy driven natural convection. Liquid PCM molecules at higher temperature rise above the surface and subsequently, the rise in temperature in bottom and central surfaces are slower than the top. 


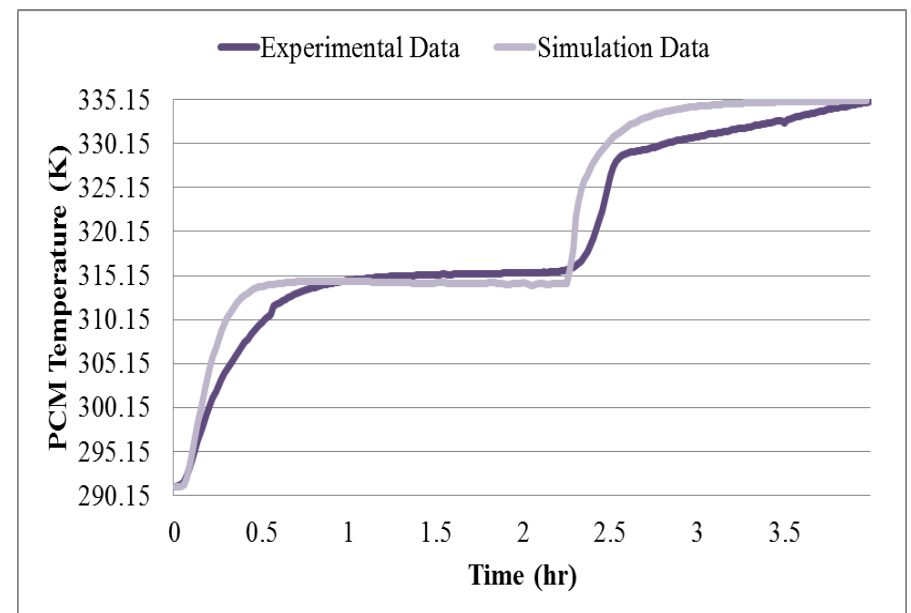

Fig. 12 Validation of numerical simulation results with experimental results. Inlet temperature and mass flow rate in both cases are set to $335.15 \mathrm{~K}$ and $2 \mathrm{lpm}$.

\section{CONCLUSION}

This paper is focused on identifying viable design solutions that would assure rapid charging and discharging rate of solar based LHS system. Numerical analyses are conducted on two dimensional transient computational models of longitudinal fins based LHS system. Parametric investigations have indicated that longitudinal fins length is an effective parameter as compared to fins thickness. Moreover, inlet temperature of HTF has shown significant influence on thermal performance as compared to volume flow rate. Numerical results are validated by experimental examination of LHS system. Both results have shown a good agreement. Shell and tube with longitudinal fins has exhibited an excellent thermal performance by quick charging and discharging rate of LHS system. Due to rapid charging rate, higher thermal storage capacity of LHS system can be achieved in shorter period of time. Similarly, prompt availability of required thermal energy can be guaranteed by adapting to the unique design of LHS system. Also, the LHS unit is flexible to scale-up or to operate in series in order to meet required energy demands. The improved thermal performance can yield good spatial, time and economic advantages in number of domestic and industrial applications.

\section{ACKNOWLEDGMENTS}

This research is joint funded by Bournemouth University, UK and National University of Sciences and Technology (NUST), Pakistan within their international collaboration initiative. The authors would also like to acknowledge Future Energy Source (FES) Ltd, UK for providing in-kind support and experimental resources during this research.

\section{NOMENCLATURE}

\begin{tabular}{|ll|}
\hline$C_{p}$ & Specific heat $(\mathrm{kJ} / \mathrm{kg} . \mathrm{K})$ \\
\hline
\end{tabular}

\begin{tabular}{|c|c|}
\hline $\mathbf{F}$ & Buoyant force $(\mathrm{Pa} / \mathrm{m})$ \\
\hline$f$ & Fraction of PCM in solid and liquid phase \\
\hline $\mathbf{g}$ & Gravitational acceleration $\left(\mathrm{m} / \mathrm{s}^{2}\right)$ \\
\hline$H$ & Specific enthalpy (MJ) \\
\hline$k$ & Thermal conductivity (W/m. K) \\
\hline$L$ & Latent heat $(\mathrm{kJ} / \mathrm{kg})$ \\
\hline$T$ & Temperature $(\mathrm{K})$ \\
\hline$T_{p c}$ & Phase transition temperature $(\mathrm{K})$ \\
\hline$p$ & Pressure $(\mathrm{Pa})$ \\
\hline$q$ & Heat source term $\left(\mathrm{W} / \mathrm{m}^{3}\right)$ \\
\hline$S \mathbf{u}$ & Momentum source term \\
\hline U & Velocity vector $(\mathrm{m} / \mathrm{s})$ \\
\hline \multicolumn{2}{|c|}{ Greek symbols } \\
\hline$\alpha$ & Small constant value \\
\hline$\beta$ & Coefficient of thermal expansion $(1 / \mathrm{K})$ \\
\hline$\kappa$ & Morphology constant of mushy zone \\
\hline$\rho$ & Density $\left(\mathrm{kg} / \mathrm{m}^{3}\right)$ \\
\hline$\mu$ & Dynamic viscosity $(\mathrm{kg} / \mathrm{m} . \mathrm{s})$ \\
\hline \multicolumn{2}{|c|}{ Subscripts } \\
\hline$S$ & Solid phase of PCM \\
\hline$l$ & Liquid phase of PCM \\
\hline \multicolumn{2}{|c|}{ Abbreviations } \\
\hline HTF & Heat transfer fluid \\
\hline LHS & Latent heat storage \\
\hline PCM & Phase change material \\
\hline $\mathrm{vfr}$ & Volume flow rate \\
\hline $1 \mathrm{pm}$ & Liter per minute \\
\hline
\end{tabular}




\section{REFERENCES}

[1] International Energy Agency (IEA), 2015, "Energy and Climate Change " Proc. 21st UN Conference of the Parties (COP21).

[2] Suranovic, S., 2013, "Fossil fuel addiction and the implications for climate change policy," Global Environmental Change, 23(3), pp. 598-608.

[3] Modi, A., Bühler, F., Andreasen, J. G., and Haglind, F., 2017, "A review of solar energy based heat and power generation systems," Renewable and Sustainable Energy Reviews, 67, pp. 1047-1064.

[4] Helvaci, H., and Khan, Z. A., 2015, "Mathematical modelling and simulation of multiphase flow in a flat plate solar energy collector," Energy Conversion and Management, 106, pp. 139-150.

[5] Helvaci, H., and Khan, Z. A., 2016, "Experimental study of thermodynamic assessment of a small scale solar thermal system," Energy Conversion and Management, 117, pp. 567576.

[6] Khan, Z., Khan, Z., and Tabeshf, K., 2016, "Parametric investigations to enhance thermal performance of paraffin through a novel geometrical configuration of shell and tube latent thermal storage system," Energy Conversion and Management, 127, pp. 355-365.

[7] Morrison, D., and Abdel-Khalik, S., 1978, "Effects of phase-change energy storage on the performance of air-based and liquid-based solar heating systems," Solar Energy, 20(1), pp. 57-67.

[8] Ghoneim, A., 1989, "Comparison of theoretical models of phase-change and sensible heat storage for air and water-based solar heating systems," Solar Energy, 42(3), pp. 209-220.

[9] Sharma, A., Tyagi, V., Chen, C., and Buddhi, D., 2009, "Review on thermal energy storage with phase change materials and applications," Renewable and Sustainable energy reviews, 13(2), pp. 318-345.

[10] da Cunha, J. P., and Eames, P., 2016, "Thermal energy storage for low and medium temperature applications using phase change materials-A review," Applied Energy, 177, pp. 227-238.

[11] Dhaidan, N. S., and Khodadadi, J., 2015, "Melting and convection of phase change materials in different shape containers: A review," Renewable and Sustainable Energy Reviews, 43, pp. 449-477.

[12] Khan, Z., Khan, Z., and Ghafoor, A., 2016, "A review of performance enhancement of PCM based latent heat storage system within the context of materials, thermal stability and compatibility," Energy Conversion and Management, 115, pp. 132-158.

[13] Khodadadi, J., Fan, L., and Babaei, H., 2013, "Thermal conductivity enhancement of nanostructure-based colloidal suspensions utilized as phase change materials for thermal energy storage: a review," Renewable and Sustainable Energy Reviews, 24, pp. 418-444.
[14] Fan, L., and Khodadadi, J., 2011, "Thermal conductivity enhancement of phase change materials for thermal energy storage: a review," Renewable and Sustainable Energy Reviews, 15(1), pp. 24-46.

[15] Salunkhe, P. B., and Shembekar, P. S., 2012, "A review on effect of phase change material encapsulation on the thermal performance of a system," Renewable and Sustainable Energy Reviews, 16(8), pp. 5603-5616.

[16] Giro-Paloma, J., Martínez, M., Cabeza, L. F., and Fernández, A. I., 2016, "Types, methods, techniques, and applications for Microencapsulated Phase Change Materials (MPCM): A review," Renewable and Sustainable Energy Reviews, 53, pp. 1059-1075.

[17] 2016, "Rubitherm ${ }^{\circledR}$ Technologies $\mathrm{GmbH}$, http://www.rubitherm.eu/en/."

[18] Gray, D. D., and Giorgini, A., 1976, "The validity of the Boussinesq approximation for liquids and gases," International Journal of Heat and Mass Transfer, 19(5), pp. 545-551.

[19] Nield, D. A., and Bejan, A., 2006, Convection in porous media, Springer Science \& Business Media. 